\title{
Níveis de aminoácidos sulfurados totais para poedeiras semi-pesadas após a muda forçada
}

\author{
Total sulfur amino acids levels for Semi heavy weight laying hens \\ after forced molt
}

\begin{abstract}
Antonio Carlos de Laurentiz ${ }^{1}$ Rosemeire da Silva Filardi $^{2}$ Eliana Aparecida Rodrigues ${ }^{1}$ Otto Mack Junqueira ${ }^{3}$ Elenice Maria Casartelli ${ }^{1}$ Karina Ferreira Duarte $^{4}$
\end{abstract}

\section{RESUMO}

Cento e sessenta e duas poedeiras semipesadas anteriormente submetidas à muda forçada foram distribuídas em um delineamento inteiramente ao acaso, com três tratamentos e nove repetições de seis aves para cada. Os tratamentos consistiram no fornecimento de rações contendo 0,45, 0,60 e $0,75 \%$ de aminoácidos sulfurados totais (AAST) durante 30 dias após o término da muda forçada (fase de pós-muda). Após os 30 dias, cada um dos tratamentos adotados na fase de pós-muda foi desmembrado nos mesmos níveis de AAST, compondo, portanto, um delineamento inteiramente ao acaso em esquema fatorial $3 \times 3$ (3 níveis de AAST da fase pós-muda - 0,45; 0,60 e 0,75\% × 3 níveis de AAST na fase de produção - 0,45; 0,60 e 0,75\%), sendo os tratamentos nesta fase compostos de três repetições de seis aves cada. Na fase de pós-muda, o menor nível de AAST determinou menores valores para consumo de ração $(P<0,01)$, consumo de AAST $(P<0,01)$ e peso corporal $(P<0,01)$. Na fase de produção do segundo ciclo produtivo, o único parâmetro afetado $(P<0,05)$ pelo nível de AAST utilizado na fase de pósmuda foi o peso do ovo, sendo o menor valor obtido com o nível de 0,45\%. O nível de 0,45\% de AAST utilizado na fase de produção não atendeu às exigências da aves, determinando pior desempenho produtivo $(P<0,01)$. O nível de $0,60 \%$ de AAST foi suficiente para a fase de pós-muda e para o segundo ciclo de produção.

Palavras-chave: aminoácidos sulfurados, muda forçada, poedeiras semi-pesadas, qualidade de ovos.

\section{ABSTRACT}

One hundred and sixty two brown laying hens after the induced molt were randomly assigned to three treatments with nine replications and six birds each. The treatments consisted of $0.45,0.60$ and $0.75 \%$ of total sulfur amino acids (TSAA) in the diets for 30 days after the end of induced molt (postmolt phase). After 30 days, each one of the treatments used in the postmolt phase was dismembered in the same TSAA levels, composing therefore a completely randomized desing in a factorial arrangement $3 \times 3$ (3 levels of TSAA in the postmolt phase -0.45 , 0.60 and $0.75 \% \times 3$ TSAA levels in the production phase -0.45 , 0.60 and $0.75 \%$ ). The treatments in the production phase were composed of three replications of six birds each. At the production phase the performance and egg quality were evaluated for 4 periods of 21 days. At postmolt phase the lower TSAA level $(0.45 \%)$ determined lower values $(P<0.01)$ for feed intake, TSAA intake and body weight. The TSAA levels used in the postmolt phase affected $(P<0.05)$ only the egg weight and the smaller weight were determined by $0.45 \%$ of TSAA. The level of $0.45 \%$ of TSAA used in the production phase did not attend the bird requirements, and determined worse performance $(P<0.01)$. The level of $0.60 \%$ of TSAA may be recommended for postmolt phase and the second production period.

Key words: egg quality, molting, semi heavy weight laying hens, sulfur amino acid.

\section{INTRODUÇÃo}

A muda natural de penas é um evento que ocorre anualmente em aves adultas de diversas espécies. O processo envolve renovação de penas, redução em até $40 \%$ do peso corporal da ave e pausa na postura; isso devido à regressão de seu aparelho

\footnotetext{
${ }^{1}$ Zootecnista, Doutorando, Faculdade de Ciências Agrárias e Veterinárias (FCAV), Universidade Estadual Paulista (UNESP), Jaboticabal. 'Zootecnista, Pós-doutorado, FCAV, UNESP, Jaboticabal, Av. Líbero Badaró, 810, Centro, 14870-540, Jaboticabal, SP. E-mail: rofilardi@ig.com.br.

${ }^{3}$ Médico veterinário, Professor Titular, FCAV, UNESP, Jaboticabal.

${ }^{4}$ Médico veterinário, Mestrando, FCAV, UNESP, Jaboticabal.
} 
reprodutor, que após a pausa se torna rejuvenescido para iniciar um novo ciclo de postura (MROSOVSKY \& SHERRY, 1980). Na exploração comercial de ovos, utiliza-se a indução artificial da muda em galinhas em final de produção, com o objetivo de aproveitar mais um ciclo produtivo em lotes com bom desempenho, aliado a um maior preço de mercado para os ovos de maior tamanho. Entretanto, uma produtividade satisfatória durante o segundo ciclo só é atingida quando as aves têm condições nutricionais adequadas para garantir uma boa recuperação dos componentes corporais e retorno rápido à produção de ovos (MENDONÇA \& LIMA, 1999).

No período de pós-muda, um dos principais nutrientes requeridos pelas aves são os aminoácidos, destacando-se os aminoácidos sulfurados totais (AAST). ANDREWS et al. (1987) relataram que o fornecimento de dieta pós-muda contendo $0,65 \%$ de metionina+cistina determinou maior produção de ovos, em relação a uma dieta com $0,60 \%$ de metionina+cistina. Entretanto, como evidenciado nos estudos de CALDERON \& JENSEN (1990), o aumento na produção de ovos em resposta ao aumento nos níveis de metionina+cistina também dependem do nível de proteína na dieta. Os mesmos autores determinaram que, em dietas com $13 \%$ de proteína, as exigências de metionina+cistina ficaram na faixa de $0,48 \%$ a $0,55 \%$, em dietas com $16 \%$ de proteína entre $0,59 \%$ a $0,61 \%$, e em dietas com $19 \%$ de proteína, entre $0,60 \%$ e $0,70 \%$.

MENDONÇA \& LIMA (1999), estudando o efeito de rações pós-muda contendo dois níveis de proteína na dieta e diferentes níveis de AAST, observaram que o aumento de aminoácidos sulfurados determinou maior peso do ovo, sem contudo aumentar a produção de ovos. Por outro lado, observaram que o aumento nos níveis desses aminoácidos e, conseqüentemente, aumento no tamanho dos ovos, determinou baixa qualidade de casca. Segundo WALDROUP \& HELLWING (1995) e HARMS et al. (1998), existe uma alta relação entre peso do ovo e qualidade da casca, a qual pode estar associada ao nível de metionina+cistina na ração, pois ocorre aumento no peso do ovo sem que haja alteração na deposição de casca.

Sendo assim, o objetivo do presente experimento foi avaliar o efeito de diferentes níveis de AAST na fase de pós-muda e produção sobre o desempenho de poedeiras semipesadas em segundo ciclo.

\section{MATERIAL E MÉTODOS}

Às 68 semanas de idade, 200 poedeiras comercias de ovos marrons foram submetidas à muda forçada através da restrição total de alimento até apresentarem cerca de $20 \%$ de perda de peso corporal (14 dias). Após os 14 dias, foram selecionadas e pesadas 162 aves para formação das parcelas experimentais. Durante o período de pós-muda, ou seja, até as aves atingirem 5\% de produção (30 dias), as aves foram distribuídas em um delineamento inteiramente ao acaso, com três tratamentos de nove repetições de seis aves para cada. Os tratamentos consistiram no fornecimento de rações contendo 0,45; 0,60 e $0,75 \%$ de AAST. Após os 30 dias, cada um dos tratamentos adotados na fase de pós-muda foi desmembrado nos mesmos níveis de AAST, compondo, portanto, um delineamento inteiramente ao acaso em esquema fatorial 3x3 (3 níveis de AAST da fase pós-muda - 0,45; 0,60 e 0,75\% x 3 níveis de AAST na fase de produção - 0,45; 0,60 e 0,75\%), sendo os tratamentos compostos de três repetições de 6 aves cada. As rações experimentais foram formuladas de acordo com as recomendações de ROSTAGNO et al. (2000), sendo isonutritivas e variando apenas nos níveis de AAST de acordo com os tratamentos (Tabela 1).

Na fase de pós-muda (30 dias), foram avaliados o consumo de ração (g/ave/dia), consumo de AAST (mg/ave/dia) e peso corporal (g). Na fase de produção, foram avaliados parâmetros de desempenho e de qualidade dos ovos durante 4 ciclos de 21 dias, compreendendo o período de 74 a 86 semanas de idade. Os parâmetros de produção avaliados foram o consumo de ração (g/ave/dia), produção de ovos (\%), peso dos ovos (g), massa de ovos (g) e conversão alimentar (kg de ração consumida/kg de ovos produzidos e por dúzia de ovos). Durante os dois últimos dias de cada ciclo três ovos por parcela foram identificados e procedida a avaliação da Unidade Haugh, porcentagem e espessura de casca. No mesmo período, para a determinação do peso médio dos ovos e gravidade específica foram utilizados todos os ovos produzidos na parcela no respectivo dia.

As análises de variância foram realizadas utilizando-se o programa SAS (1996) e as médias comparadas pelo Teste de Tukey ao nível de 5\% de probabilidade.

\section{RESULTADOS E DISCUSSÃO}

Na tabela 2, são apresentadas as médias para consumo de ração, consumo de AAST e peso 
Tabela 1 - Composição e níveis nutricionais calculados para as rações experimentais.

\begin{tabular}{lccc}
\hline \multirow{2}{*}{\multicolumn{1}{c}{ Ingredientes (\%) }} & \multicolumn{3}{c}{$\begin{array}{c}\text { Nível de aminoácidos } \\
\text { sulfurados totais }\end{array}$} \\
\cline { 2 - 4 } & $0,45 \%$ & $0,60 \%$ & $0,75 \%$ \\
\hline Milho & 38,52 & 71,25 & 71,10 \\
Farelo de soja & 23,69 & 17,80 & 17,59 \\
Amido de milho & 16,33 & 0,00 & 0,00 \\
Calcário calcítico & 7,60 & 7,80 & 7,70 \\
Casca de arroz & 6,84 & 0,31 & 0,62 \\
Óleo de soja degomado & 4,34 & 0,00 & 0,00 \\
Fosfato bicálcico & 1,70 & 1,63 & 1,63 \\
Cloreto de sódio & 0,48 & 0,49 & 0,49 \\
DL-metionina (98\%) & 0,00 & 0,10 & 0,25 \\
L-Lisina (78\%) & 0,00 & 0,12 & 0,12 \\
Suplemento min+vit ${ }^{1}$ & 0,50 & 0,50 & 0,50 \\
Total & 100,00 & 100,00 & 100,00 \\
\hline Níveis calculados & & & \\
Energia metabolizável (kcal/kg) & 2.850 & 2.850 & 2.850 \\
Proteína bruta (\%) & 14,40 & 14,40 & 14,40 \\
Cálcio (\%) & 3,50 & 3,50 & 3,50 \\
Fósforo disponível (\%) & 0,39 & 0,39 & 0,39 \\
Fibra bruta (\%) & 4,70 & 2,70 & 2,78 \\
Lisina (\%) & 0,78 & 0,78 & 0,78 \\
Metionina (\%) & 0,22 & 0,33 & 0,49 \\
Aminoácidos sulfurados totais (\%) & 0,45 & 0,60 & 0,75 \\
Sódio (\%) & 0,23 & 0,23 & 0,23 \\
Treonina (\%) & 0,55 & 0,55 & 0,55 \\
Triptofano (\%) & 0,18 & 0,16 & 0,16 \\
\hline & & & \\
\hline
\end{tabular}

${ }^{1}$ * Enriquecimento por quilograma de ração: Vitamina A 8.000UI; Vitamina D3 - 2.000UI; Vitamina E - 50mg; Vitamina K3 - 3mg; Vitamina B1 - 1,5mg; Vitamina B2 - 4mg; Vitamina B6 - 0,12mg, Vitamina B12 - 15mcg; Ácido fólico - 0,6mg; Ácido pantotênico 10mg; Niacina - 30mg; Biotina - 0,1mg; Colina - 300mg; Ferro - 50mg; Cobre - 10mg; Zinco - 70mg; Manganês - 100mg; Iodo - 1mg; Selênio - 0,3mg; Antioxidante 50mg.

corporal obtidas durante o período de pós-muda. Observou-se que os diferentes níveis de AAST aplicados durante a fase de pós-muda afetaram significativamente $(\mathrm{P}<0,01)$ os parâmetros analisados, sendo que o nível de $0,45 \%$ de AAST determinou menor consumo de ração, menor consumo de AAST e menor peso corporal, embora este peso tenha sido semelhante ao proporcionado pelo nível de $0,60 \%$ de AAST. MENDONÇA \& LIMA (1999), avaliando os efeitos da suplementação de metionina em rações contendo diferentes níveis de proteína sobre o desempenho de poedeiras após a muda forçada, também observaram que a diminuição nos níveis de AAST determinou redução no consumo de ração, entretanto não afetou o peso corporal, quando os níveis de AAST variaram entre 0,535 a $0,635 \%$, em uma ração contendo $14,5 \%$ de proteína bruta.

A ingestão de AAST observada no presente estudo para o tratamento com $0,45 \%$ de AAST (443mg dia ${ }^{-1}$ ) apresenta-se abaixo da recomendação de $645 \mathrm{mg} \mathrm{dia}^{-1}$ do NRC (1994), evidenciando, neste caso, o não atendimento das exigências por AAST. Entretanto, em função do maior teor de fibra apresentado por esse tratamento (4,7\% de FB), provavelmente a menor ingestão foi determinada pelo efeito da fibra.

Os efeitos de diferentes níveis de AAST, utilizados na fase de pós-muda e na fase de produção do segundo período de postura, sobre o desempenho no período de 74 a 86 semanas de idade podem ser observados na tabela 3. Para nenhum dos parâmetros avaliados, ocorreu interação significativa entre os níveis de aminoácidos sulfurados utilizados na fase de pósmuda e na fase de produção $(\mathrm{P}>0,05)$. Os níveis de AAST utilizados durante a fase de pós-muda não determinaram diferenças $(\mathrm{P}>0,05)$ no consumo de ração, produção de ovos e conversão alimentar por kg ou por dúzia de ovos durante o intervalo avaliado no segundo ciclo produtivo, entretanto tiveram efeito significativo $(\mathrm{P}<0,05)$ sobre o peso médio do ovo. O menor nível de AAST (0,45\%), utilizado durante a fase de pós-muda, determinou durante a

Tabela 2 - Médias para consumo de ração, consumo de aminoácidos sulfurados e peso corporal em função dos níveis de aminoácidos sulfurados utilizados na fase de pós-muda.

\begin{tabular}{lccr}
\hline \multicolumn{1}{c}{ Aminoácidos sulfurados } & Consumo de ração (g/dia) & Consumo de aminoácidos sulfurados (mg/dia) & Peso corporal (g) \\
\hline 0,45 & $98,57 \mathrm{~b}$ & $443 \mathrm{c}$ & $1765 \mathrm{~b}$ \\
0,60 & $106,03 \mathrm{a}$ & $636 \mathrm{~b}$ & $1816 \mathrm{ab}$ \\
0,75 & $108,27 \mathrm{a}$ & $812 \mathrm{a}$ & $1892 \mathrm{a}$ \\
Valor de F & $7,618 * *$ & $285,3 * *$ & $6,67 * *$ \\
CV $(\%)$ & 5,29 & 5,19 & 4,06 \\
\hline
\end{tabular}

Médias na coluna, para cada fator, seguidas de diferentes letras diferem entre si pelo teste de Tukey $(\mathrm{P}<0,05)$.

$* *(\mathrm{P}<0,01)$.

Ciência Rural, v.35, n.1, jan-fev, 2005. 
Tabela 3 - Médias para os parâmetros de desempenho obtidos em função dos níveis de AAST utilizados nas fases de pós-muda e produção.

\begin{tabular}{|c|c|c|c|c|c|c|}
\hline \multirow[t]{2}{*}{ AAST } & $\begin{array}{l}\text { Consumo de ração } \\
\text { (g/dia) }\end{array}$ & $\begin{array}{c}\text { Produção de ovos } \\
\text { (\%) }\end{array}$ & $\begin{array}{l}\text { Peso do ovo } \\
\text { (g) }\end{array}$ & $\begin{array}{c}\text { Massa de ovos } \\
\text { (g) }\end{array}$ & $\begin{array}{l}\text { Conversão alimentar } \\
\quad\left(\mathrm{kg} \mathrm{kg}^{-1}\right)\end{array}$ & $\begin{array}{c}\text { Conversão } \\
\text { alimentar } \\
\left(\mathrm{kg} \text { dúzia }^{-1}\right)\end{array}$ \\
\hline & \multicolumn{6}{|c|}{ Efeito dos níveis da fase de pós-muda (PM) } \\
\hline 0,45 & 103,68 & 81,08 & $62,77 \mathrm{~b}$ & 45,62 & 2,316 & 1,798 \\
\hline 0,60 & 101,75 & 81,85 & 64,95 a & 46,16 & 2,308 & 1,731 \\
\hline$\underline{0,75}$ & 105,64 & 80,77 & 65,05 a & 45,26 & 2,395 & 1,867 \\
\hline AAST & \multicolumn{6}{|c|}{ Efeito dos níveis da fase de produção (PR) } \\
\hline 0,45 & $94,15 b$ & $70,47 \mathrm{~b}$ & $61,82 \mathrm{~b}$ & $36,63 \mathrm{~b}$ & 2,643 a & 1,960 a \\
\hline 0,60 & 105,98 a & 84,17 a & 65,05 a & 48,70 a & $2,206 \mathrm{~b}$ & $1,721 \mathrm{~b}$ \\
\hline 0,75 & $110,94 \mathrm{a}$ & $89,06 \mathrm{a}$ & 65,89 a & $51,71 \mathrm{a}$ & $2,172 \mathrm{~b}$ & $1,715 \mathrm{~b}$ \\
\hline \multicolumn{7}{|c|}{ Valores de $\mathrm{F}$} \\
\hline PM & $0,66 \mathrm{~ns}$ & $0,04 \mathrm{~ns}$ & $5,09 *$ & $0,05 \mathrm{~ns}$ & $0,40 \mathrm{~ns}$ & $1,44 \mathrm{~ns}$ \\
\hline PR & $12,96 * *$ & $11,47^{* *}$ & $14,22 * *$ & $15,65^{* *}$ & $12,09 * *$ & $6,07 * *$ \\
\hline PMxPR & $1,13 \mathrm{~ns}$ & $0,87 \mathrm{~ns}$ & $2,34 \mathrm{~ns}$ & $0,94 \mathrm{~ns}$ & $0,43 \mathrm{~ns}$ & $0,28 \mathrm{~ns}$ \\
\hline CV (\%) & 6,93 & 10,50 & 2,66 & 13,24 & 9,69 & 9,45 \\
\hline
\end{tabular}

Médias na coluna, para cada fator, seguidas de diferentes letras diferem entre si pelo teste de Tukey $(\mathrm{P}<0,05)$

** $(\mathrm{P}<0,01), *(\mathrm{P}<0,05), \mathrm{ns}=$ não significativo $(\mathrm{P}>0,05)$.

fase de produção do segundo ciclo produtivo menor peso do ovo em relação aos demais níveis $(\mathrm{P}<0,05)$, embora não tenha determinado efeito negativo sobre a produção de ovos.

Na fase de produção do segundo ciclo, os níveis de AAST determinaram diferenças significativas $(\mathrm{P}<0,01)$ para todos os parâmetros de desempenho avaliados. O menor nível de AAST $(0,45 \%)$ determinou o pior desempenho em relação aos níveis de $0,60 \%$ e $0,75 \%$, que não diferiram entre si. Desta forma, o menor consumo de ração, determinado pelo maior nível de fibra para o nível de $0,45 \%$ de AAST, determinou menor produção, menor peso e massa de ovos, e ainda, pior conversão alimentar, tanto por kg de ovo como por dúzia de ovos produzidos.

A diminuição na produção e no peso de ovos como reflexo da menor ingestão de AAST também foi observada por BARBOSA (1997) testando o nível de $0,45 \%$ de AAST em rações para poedeiras leves e semipesadas em segundo ciclo de produção. O comprometimento no desempenho das aves recebendo menores níveis de AAST poderia ser explicado pelo não atendimento das exigências para esses de aminoácidos, e ainda pelo imbalanço de aminoácidos decorrente da modificação na composição de aminoácidos da dieta pela adição de aminoácidos em excesso (HARPER et al, 1970).

Considerando-se os níveis de $0,60 \%$ e 0,75\% de AAST observa-se que o desempenho das aves foi semelhante. AHMAD \& ROLAND (2003), avaliando os efeitos dos níveis de AAST e temperatura ambiente sobre o desempenho de poedeiras, também constataram que a ingestão de vários níveis de AAST não influenciou ou teve pouca influência sobre a produção de ovos, conversão alimentar, gravidade específica ou mortalidade das aves. Entretanto, estes autores observaram que o aumento nos níveis de AAST contribuem para o aumento no peso do ovo.

Na tabela 4, são apresentadas as médias para os parâmetros de qualidade interna e externa dos ovos. Nela, observa-se que não ocorreram interações significativas $(\mathrm{P}>0,05)$ entre os níveis de AAST utilizados na fase de pós-muda e na fase de produção do segundo ciclo produtivo das aves.

De forma semelhante ao observado para os parâmetros de desempenho, os níveis de AAST utilizados na fase de pós-muda não influenciaram significativamente $(\mathrm{P}>0,05)$ os parâmetros de qualidade interna e externa dos ovos avaliados na fase de produção do segundo ciclo produtivo das aves. Os níveis utilizados na fase de produção determinaram diferenças significativas $(P<0,05)$ apenas para a porcentagem de casca, sendo que, no nível de 0,45\% de AAST, observou-se a maior porcentagem de casca, enquanto entre os níveis de $0,60 \%$ e $0,75 \%$ os valores foram semelhantes. Os níveis de $0,60 \%$ e $0,75 \%$ de AAST utilizado na fase de produção do segundo ciclo resultaram em menor porcentagem de casca $(\mathrm{P}<0,05)$. De acordo com WALDROUP \& HELLWING (1995) e HARMS et al. (1998), maiores níveis de AAST podem determinar aumento no peso e piora na qualidade de casca, isso em decorrência da deposição de casca permanecer inalterada. 
Tabela 4 - Médias para os parâmetros de qualidade interna e externa dos ovos obtidos em função dos níveis de AAST utilizados nas fases de pós-muda e produção.

\begin{tabular}{|c|c|c|c|c|}
\hline \multirow{2}{*}{ AAST } & Unidade Haugh & Porcentagem de casca (\%) & Espessura de casca (mm) & Gravidade específica $\left(\mathrm{g} \mathrm{cm}^{-3}\right)$ \\
\hline & \multicolumn{4}{|c|}{ Efeito dos níveis da fase de pós-muda (PM) } \\
\hline 0,45 & 89,15 & 9,74 & 372 & 1,0908 \\
\hline 0,60 & 89,72 & 9,71 & 364 & 1,0900 \\
\hline$\underline{0,75}$ & 87,55 & 9,57 & 366 & 1,0899 \\
\hline AAST & \multicolumn{4}{|c|}{ Efeito dos níveis da fase de produção (PR) } \\
\hline 0,45 & 90,43 & 9,99 a & 372 & 1,0931 \\
\hline 0,60 & 86,77 & $9,54 \mathrm{~b}$ & 366 & 1,0903 \\
\hline$\underline{0,75}$ & 89,24 & $9,48 \mathrm{~b}$ & 364 & 1,0891 \\
\hline \multicolumn{5}{|c|}{ Valores de F } \\
\hline PM & $1,21 \mathrm{~ns}$ & $0,60 \mathrm{~ns}$ & $1,94 \mathrm{~ns}$ & $0,55 \mathrm{~ns}$ \\
\hline PR & 3,29 ns & $6,01^{*}$ & $2,21 \mathrm{~ns}$ & 3,21 ns \\
\hline PMxPR & 1,20 ns & $0,62 \mathrm{~ns}$ & $1,55 \mathrm{~ns}$ & 1,37 ns \\
\hline CV (\%) & 3,47 & 3,52 & 2,32 & 0,17 \\
\hline
\end{tabular}

Médias na coluna, para cada fator, seguidas de diferentes letras diferem entre si pelo teste de Tukey $(\mathrm{P}<0,05)$.

** $(\mathrm{P}<0,01), *(\mathrm{P}<0,05), \mathrm{ns}=$ não significativo $(\mathrm{P}>0,05)$.

\section{CONCLUSÃO}

Os níveis de AAST utilizados na fase de pós-muda exerceram efeito na fase de produção do segundo ciclo produtivo sobre o peso do ovo. Em função da redução na ingestão, o nível de 0,45\% de AAST não atendeu as exigências da aves, determinando pior desempenho produtivo. Como não houve diferença entre os níveis de 0,60 e 0,75\% de AAST, o nível de $0,60 \%$ de AAST é suficiente para o período de pós-muda e segundo ciclo de produção.

\section{AGRADECIMENTOS}

Agradecimento especial à Fundação de Auxílio à Pesquisa do Estado de São Paulo pelo suporte financeiro (Processo nº 00/12377-1 ).

\section{REFERÊNCIAS BIBLIOGRÁFICAS}

AHMAD, H.A.; ROLAND, D.A. Effect of environmental temperature and total sulfur amino acids on performance and profitability of laying hens: an econometric approach. Journal of Applied Poultry Research, v.12, p.476-482, 2003.

ANDREWS, D.K. et al. Effect of lighting program and nutrition on reproductive performance and molted single comb white leghorn hens. Poultry Science, v.66, p.1298-1305, 1987.

BARBOSA, B.A.C. Exigências nutricionais em metionina+cistina e lisina para galinhas poedeiras leves e semi-pesadas, no segundo ciclo de produção. 1997. 87f. Dissertação (Mestrado em Zootecnia) -
Curso de Pós-graduação em Zootecnia, Universidade Federal de Viçosa.

CALDERON, V.M.; JENSEN, L.S. The requirement for sulfur amino acid by laying hens as influenced by protein concentration. Poultry Science, v.69, p.934944, 1990.

HARMS, R.H. et al. The influence of methionine on commercial laying hens. Journal of Applied Poultry Research, v.7, 45-52, 1998.

HARPER, A.E. et al. Effects of ingestion of disproportionate amounts of amino acids. Phisiological Reviews, v. 50, p.428-558, 1970.

MENDONÇA Jr, C.X.; LIMA, F.R. Efeito dos níveis de proteína e de metionina da dieta sobre o desempenho de galinhas poedeiras após a muda forçada. Brazilian Journal Veterinary Research and Animal Science, v.36, p.332338, 1999.

MROSOVSKY, N.; SHERRY, D.F. Animal anorexias. Science, v.207, p. 837-842, 1980.

NATIONAL RESEARCH COUNCIL. NRC. Nutrient requirements of Poultry. 9.ed. Washington : National Academic, 1994. 155p.

ROSTAGNO, H.S. et al. Composição de alimentos e exigências nutricionais de aves e suínos: tabelas brasileiras. Viçosa, MG: UFV, 2000. 141p.

SAS Statistical Analysis System User's Guide. 4.ed. Cary : SAS Institute, 1996. 842p.

WALDROUP, P.W.; HELLWING, H.M. Methionine and total sulfur amino acid requirements influenced by stage of production. Journal of Applied Poultry Research, v.4, p.283-292, 1995.

Ciência Rural, v.35, n.1, jan-fev, 2005. 